\title{
A cure for dyslexia?
}

\author{
A company is promoting behavioral exercises as a cure for dyslexia. Scientists worry that evaluation of the program \\ is compromised by design flaws and conflicts of interest and that responses to critics restrict academic freedom.
}

L ate last year, five editorial board members resigned from the journal Dyslexia to protest the publication of an article ${ }^{1}$ on the effects of a treatment marketed as a cure for dyslexia by a private company, Dore Achievement Centres. The new paper is a follow-up to a controversial 2003 study $^{2}$ in Dyslexia, which led to the resignation of one editorial board member and publication of nine commentaries in the journal. The company, founded by British multimillionaire Wynford Dore, continues to cite these papers to promote the treatment, despite concerns raised by scientists about the study's design and conclusions.

Dyslexia has no policy requiring disclosure of conflicts of interest, but journalists reported several potential conflicts after the paper was published. Dore Achievement Centres paid the first author, David Reynolds

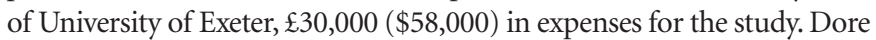
has also sponsored three Ph.D. students working in the department of the study's other author, Roderick Nicolson of the University of Sheffield, though Nicolson says that the students did not work on this study.

The editor of Dyslexia, Angela Fawcett, is a long-time collaborator of Nicolson, with whom she has published over 30 articles and book chapters. Fawcett states that she was not involved in the decision to publish the paper and that she has not received any money from Dore's companies. An investigation by Wiley, the journal's publisher, found that she had acted properly and that the paper had been peer reviewed by appropriate experts according to the journal's normal procedures.

The Dore treatment program is based on the cerebellar deficit hypothesis of dyslexia proposed by Nicolson and Fawcett. Dyslexic children have a reduced ability to process phonemes, the sounds that make up words. The cerebellum is important for the automation of motor skills and may be involved in higher cognition as well. The hypothesis proposes that abnormalities in cerebellar structure in dyslexic children lead to problems in automating language-related skills, which then impair their ability to learn reading, writing and spelling. There is evidence for ${ }^{3}$ and against ${ }^{4}$ this hypothesis, but it is plausible enough to merit serious investigation.

Even if cerebellar dysfunction does cause dyslexia, it remains to be shown that the deficits can be improved by behavioral training. Key elements of the Dore program include using a balance board, throwing and catching beanbags, and stretching and coordination exercises. The program is individually tailored and costs several thousand dollars per person. It is marketed for attention deficit hyperactivity disorder (ADHD), dyspraxia and Asperger syndrome as well as dyslexia. Dore Achievement Centres have treated over 25,000 people worldwide.

The initial study ${ }^{2}$ of the program's effectiveness examined 35 children who scored above 0.4 on Nicolson's Dyslexia Screening Test (DST), which is designed to assess the risk of dyslexia. After six months of training, the 18 children assigned to the Dore program improved more than untreated controls on 3 of 11 subtests: one-minute reading, bead threading and semantic fluency (how many animals the child can name in one minute).
The authors concluded that "benefits of the...treatment transferred significantly to cognitive skills underlying literacy."

The commentaries raised concerns about the study's design ${ }^{2}$, which Nicolson and Reynolds acknowledge "weaken the strength of

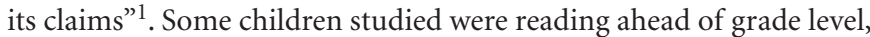
and writing and semantic fluency were above average for most children. Only six were diagnosed with dyslexia, two with dyspraxia and one with ADHD, suggesting that most subjects did not have the conditions that the Dore program is supposed to remediate. The groups were not matched on literacy before training. The control group received less intensive treatment then the experimental group, raising concerns about a placebo effect. The follow-up study ${ }^{1}$ had no control group, as control subjects received the treatment after the initial study.

Academics typically argue such disagreements in the pages of scientific journals. However, people who criticize this training program in public may hear from the company's lawyers. Max Coltheart, then president of the Specific Learning Disabilities Association of New South Wales, received such a letter after his organization posted links on its website to comments on the Dore program from the British Dyslexia Association and the International Dyslexia Association, in which the latter stated that the Dore program "is not supported by current scientific knowledge." Margaret Snowling of York University also received a letter asking that she retract a statement to the British Broadcasting Corporation that there is no scientific evidence for the efficacy of the Dore treatment.

The field of dyslexia research has more than its share of controversy, as we have noted before ${ }^{5}$, and most common treatments are slow and difficult. Under the circumstances, some practical experimentation seems in order, and we welcome the participation of commercial as well as academic groups in this venture. However, before any treatment becomes broadly accepted, it should be rigorously evaluated by researchers with no link to the company that stands to profit from a positive trial. A New York art dealer has agreed to fund such an independent study, and Peter S. Jensen, Director of the Center for the Advancement of Children's Mental Health at Columbia University, has agreed to evaluate whether a rigorous clinical trial is merited. Such a study would be a major step forward, but until an independent evaluation has been published in an academic journal, claims that the treatment has been scientifically proven cannot be supported. More importantly, parents must be able to rely on experts in the field to give their honest professional opinion about a treatment's efficacy, without interference from commercial interests or legal concerns.

\footnotetext{
1. Reynolds, D. \& Nicolson, R.I. Dyslexia published online 27 Oct 2006 (doi:10.1002/ dys.331).

2. Reynolds, D., Nicolson, R.I. \& Hambly, H. Dyslexia 9, 48-71 (2003).

3. Nicolson, R.I., Fawcett, A.J. \& Dean, P. Trends Neurosci. 24, 508-511 (2001).

4. Zeffiro, T. \& Eden, G. Trends Neurosci. 24, 512-513 (2001).

5. Nat. Neurosci. 7, 1 (2004).
} 